\title{
Soil quality indicators based recommendation to maximize sugarcane productivity in Theni district of Tamil Nadu, India
}

\author{
K. Jeevika*, B. Bakiyathu Saliha ${ }^{1}$ and M.Vijayakumar ${ }^{2}$ \\ *Department of Soil Science and Agricultural Chemistry, Vanavarayar Institute of Agriculture, Manakkadavu, \\ Pollachi - 642103 (Tamil Nadu), INDIA \\ ${ }^{2}$ Department of Soils and Environment, Agricultural College and Research Institute, Madurai - 625104 (Tamil Nadu), \\ INDIA \\ ${ }^{3}$ Department of Soil science and Agricultural Chemistry, Regional Research Station, Tamil Nadu Agricultural \\ University, Paiyur - 635 112(Tamil Nadu), INDIA \\ *Corresponding author. E-mail: jeevired5@gmail.com
}

Received: November 18, 2014; Revised received: February 21, 2015; Accepted: April 5, 2015

\begin{abstract}
An assessment study was conducted infive sugarcane yielding blocks of theni district viz., Jeyamangalam, P.C.Patti, Chinnamanur, Andipatti and Usilampatti.The cane yielding zones of the district was classified into three categories viz., low yielding (less than $75 \mathrm{t} \mathrm{ha}^{-1}$ ), medium $\left(75\right.$ to $100 \mathrm{t} \mathrm{ha}^{-1}$ ) and high yielding (more than $100 \mathrm{t} \mathrm{ha}$ $\left.{ }^{1}\right)$. The key physico-chemical and biological indicators of soil were assessed in the surface $(0-15 \mathrm{~cm})$ and subsurface $(15-30 \mathrm{~cm})$ soils samples of each zone. The indicators assessed in the low cane yielding zone reflected slightly acidic $\mathrm{pH}(6.70)$, lower CEC $\left(11.9 \mathrm{cmol}\left(\mathrm{p}^{+}\right) \mathrm{kg}^{-1}\right)$ and low organic carbon $(0.14$ percent). The positive effects of soil physico - chemical and biological indicators on the sugarcane yield was well proved through the yield data of the high yielding zone. Almost 93 percent of the farmssurveyed in the high yielding zone registered an average cane yield of $120 \mathrm{t} \mathrm{ha}^{-1}$. This may be attributed to a neutral $\mathrm{pH}$ of 7.21 , non-saline soil with an average EC of $0.36 \mathrm{dSm}^{-1}$, maximum organic carbon status ( 0.59 percent) and higher range of soil Cation Exchange Capacity (CEC) (20 to $\left.58.0 \mathrm{cmol}\left(\mathrm{p}^{+}\right) \mathrm{kg}^{-1}\right)$ which resulted in maximum cane productivity. It was concluded that application of organic matter, amendments rich in calcium and magnesium in acidic soil and application of gypsum and other amendments rich in sulphur in alkali soils of low cane yielding zone can maximize productivity of sugarcane.
\end{abstract}

Key words: Biological indicator, Physicochemical indicators, Soil quality, Sugarcane productivity

\section{INTRODUCTION}

In India, sugarcane is the second largest crop cultivated by 35 million farmers in 5 Mha of area with an annual production of 350 million tonnes of cane. Based on the recent projections, the country would need to produce 415 million tonnes of sugarcane from an area of 4.5 Mha with a sugar recovery of 11 percent to meet the per capita requirement of $35 \mathrm{~kg}$ sweetness per year by 2020 A.D (Chand, 2007). This will deplete 0.90, 0.24, 1.26 and 0.14 million tonnes of N, P, K and S respectively (Gopalasundaramet al., 2012). Tamilnadu is one of the leading sugarcane producing states of the country with an average productivity of $105 \mathrm{tha}^{-1}$. About 30 million tonnes of cane is produced annually from an area of 2.86 lakh hectares. Theni district which is situated in the western zone of Tamilnadu is a predominant sugarcane growing region. In more recent times, a considerable gap between the potential and actual cane yields has been realized in different parts of Tamilnadu and specifically in Theni district where the average yield ( $70 \mathrm{t} / \mathrm{ha}$ ) is lower than many other parts of the state. Indeed, the plateau or decreasing yield levels and declining factor productivity have been the concerns in achieving the potential yield targets. In order to make interpretation of a soil, various processes and functions need to be assessed through meaningful soil quality indicators. The indicators of a soil cover the whole range of physico-chemical and biological properties that reflect soil functions to measure under various field conditions and response to changes in climate, soil and crop management practices (Sharma and Biswapati Mandal, 2009).

Hence, the present study was undertaken to takeup an assessment of soil in the low, medium and high yielding zones of this region to diagnose the fertility related constraints, propose suitable management techniques to enhance the soil indicators within the ecosystem boundaries and maximize the sugarcane productivity in and around Theni district of Tamilnadu, India.

\section{MATERIALS AND METHODS}

Study area: Geographically the study area was located in Theni district lying at the foot of westernghats between $9^{\circ} 30^{\prime}$ and $10^{\circ} 12^{\prime}$ North latitude and $77^{\circ} 10^{\prime}$ and $77^{\circ} 42^{\prime}$ 'East longitude at 200-400 meters above sea 
level in the plains which comprises the major sugarcane growing areas. The sampling area for soil analysis was divided into three categories viz., low yielding $(<75 \mathrm{t} /$ ha), medium yielding (75- $100 \mathrm{t} / \mathrm{ha}$ ) and high yielding $(>100 \mathrm{t} / \mathrm{ha}$ ). The farms underlying these yield categories in each of the five major sugarcane growing blocks were selected for soil sampling (Fig.1). A total of 15 surface samples $(0-15 \mathrm{~cm})$ and 15 subsurface samples (15-30 cm)@3 samples per block in three replications were collected from all the five blocks covering the low, medium and high yielding zones amounting to 225 number of soil samples representing the fertility status of the sugarcane growing regions of Theni district.

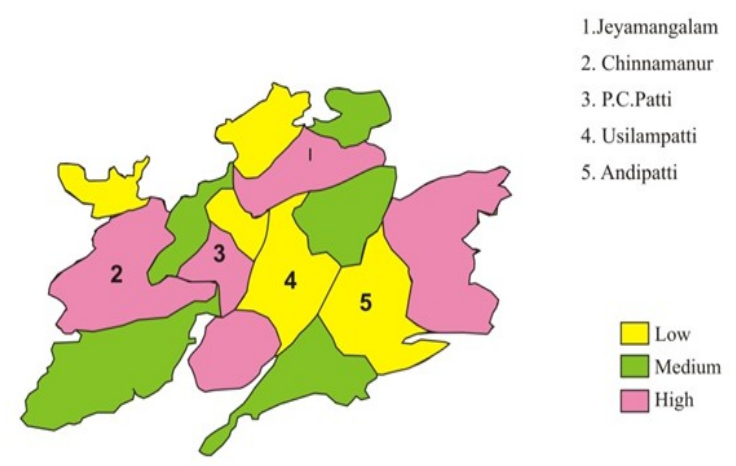

Fig.1. Categories of Low, Medium and High yielding zones of Sugarcane in different blocks of Theni district of Tamil Nadu.
Physicochemical analyses included $\mathrm{pH}, \mathrm{EC}$ was determined in 1:2 soil water suspensions using a combined $\mathrm{pH}$ meter (Jackson, 1973) and cation exchange capacity of soil was determined by using Neutral Normal Ammonium Acetate (Bower et al., 1952). Biological properties measured intermsof organic carbon by chromic acid wet digestion method as prescribed by Walkely and Black (1934). The percentage organic matter content of the surface and subsurface samples were calculated by multiplying the organic carbon content with the values of 1.724 and 2.5 , respectively.

Statistical analysis: The analytical data on soil quality parameters were processed with statistical parameters viz., range, mean, minimum, and maximum by following the methods suggested by Gomez and Gomez (1984).

\section{RESULTS AND DISCUSSION}

Physicochemical indicators of soil: The soil reaction $(\mathrm{pH})$ in the surface $(0-15 \mathrm{~cm})$ and sub-surface $(15 \mathrm{~cm}-30 \mathrm{~cm})$ samples of the low, medium and high yielding zones of sugarcane in Theni district is given in table 1 . The $\mathrm{pH}$ ranged from 5.38 to $8.50,4.74$ to 8.32 and 6.27 to 7.93 (surface) and 4.84 to $8.20,5.44$ to 8.10 and 5.90 to 7.92 (sub - surface), respectively. In surface soils about 70 percent of the samples from low yielding zone were under acidic $\mathrm{pH}$ range whereas 60 percent of the soils assessed in the high soil quality zone fall under neutral $\mathrm{pH}$ range in most of the cane growing blocks viz., Jeyamangalam, P.C. Patti, Chinnamanur, Andipatti

Table 1. Soil reaction $(\mathrm{pH})$ of various cane yielding zones of Theni district of Tamil Nadu.

\begin{tabular}{ccccccc}
\hline Sample No. & \multicolumn{3}{c}{ Surface soil (0-15 cm) } & \multicolumn{3}{c}{ Subsurface soil (15-30 cm) } \\
\cline { 2 - 6 } & Low & Medium & High & Low & Medium & High \\
\hline 1 & 6.35 & 7.25 & 7.32 & 6.24 & 7.45 & 7.27 \\
2 & 6.33 & 7.33 & 7.31 & 6.18 & 7.27 & 7.10 \\
3 & 6.20 & 7.28 & 7.08 & 6.37 & 7.19 & 7.20 \\
4 & 5.38 & 5.58 & 6.27 & 5.36 & 5.44 & 6.38 \\
5 & 5.66 & 4.74 & 6.52 & 4.84 & 5.76 & 6.55 \\
6 & 5.60 & 5.84 & 6.53 & 6.54 & 5.58 & 5.90 \\
7 & 6.47 & 6.50 & 7.13 & 6.27 & 6.60 & 6.92 \\
8 & 6.12 & 6.72 & 6.90 & 6.13 & 6.75 & 7.13 \\
9 & 6.06 & 6.81 & 7.16 & 6.12 & 6.78 & 7.06 \\
10 & 6.36 & 6.87 & 7.80 & 6.48 & 6.32 & 7.86 \\
11 & 6.27 & 6.34 & 7.89 & 6.33 & 6.36 & 7.92 \\
12 & 8.25 & 6.47 & 7.93 & 8.10 & 7.84 & 7.46 \\
13 & 8.48 & 8.32 & 7.50 & 8.20 & 7.93 & 7.43 \\
14 & 8.50 & 8.00 & 7.41 & 8.13 & 8.10 & 7.47 \\
15 & 8.43 & 8.14 & 7.46 & 8.13 & 7.95 & 7.47 \\
\hline Max. & 8.50 & 8.32 & 7.93 & 8.20 & 8.10 & 7.92 \\
Min. & 5.38 & 4.74 & 6.27 & 4.84 & 5.44 & 5.90 \\
\hline Mean & 6.70 & 6.81 & 7.21 & 6.65 & 6.89 & 7.14 \\
SD & 1.12 & 0.98 & 0.50 & 1.04 & 0.88 & 0.54 \\
CV & 16.7 & 14.3 & 6.9 & 16.3 & 12.8 & 7.6 \\
\hline
\end{tabular}


Table 2. Soil Electrical Conductivity $\left(\mathrm{dS} \mathrm{m}^{-1}\right)$ of various cane yielding zones of Theni district of Tamil Nadu.

\begin{tabular}{ccccccc}
\hline \multirow{2}{*}{$\begin{array}{c}\text { Sample } \\
\text { No. }\end{array}$} & \multicolumn{3}{c}{ Surface soil (0-15 cm) } & \multicolumn{3}{c}{ Subsurface soil (15-30 cm) } \\
\cline { 2 - 6 } & Low & Medium & High & Low & Medium & High \\
\hline 1 & 0.52 & 0.45 & 0.23 & 0.16 & 0.55 & 0.48 \\
2 & 0.56 & 0.46 & 0.23 & 0.17 & 0.53 & 0.53 \\
3 & 0.53 & 0.49 & 0.18 & 0.21 & 0.58 & 0.5 \\
4 & 0.39 & 0.13 & 0.13 & 0.47 & 0.12 & 0.1 \\
5 & 0.41 & 0.15 & 0.1 & 0.38 & 0.31 & 0.13 \\
6 & 0.39 & 0.17 & 0.15 & 0.4 & 0.23 & 0.14 \\
7 & 0.58 & 0.3 & 0.48 & 0.27 & 0.47 & 0.58 \\
8 & 0.63 & 0.2 & 0.59 & 0.21 & 0.56 & 0.04 \\
9 & 0.63 & 0.55 & 0.23 & 0.98 & 0.53 & 0.22 \\
10 & 0.48 & 0.42 & 0.27 & 0.44 & 0.27 & 0.26 \\
11 & 0.57 & 0.23 & 0.24 & 0.56 & 0.23 & 0.21 \\
12 & 0.43 & 0.28 & 0.23 & 0.42 & 0.37 & 0.3 \\
13 & 0.36 & 0.35 & 0.33 & 0.37 & 0.33 & 0.33 \\
14 & 0.44 & 0.35 & 0.34 & 0.46 & 0.35 & 0.35 \\
15 & 0.34 & 0.33 & 0.21 & 0.35 & 0.34 & 0.33 \\
\hline Max. & 0.63 & 0.55 & 0.59 & 0.98 & 0.58 & 1.04 \\
Min. & 0.34 & 0.13 & 0.1 & 0.16 & 0.12 & 0.10 \\
\hline Mean & 0.58 & 0.32 & 0.36 & 0.45 & 0.34 & 0.33 \\
SD & 0.10 & 0.14 & 0.15 & 0.20 & 0.14 & 0.24 \\
CV & 20.1 & 40.6 & 49.4 & 57.9 & 42.2 & 72.4 \\
\hline
\end{tabular}

Table 3. Cation exchange capacity $\left(\mathrm{c} \mathrm{mol}\left(\mathrm{p}^{+}\right) \mathrm{kg}^{-1}\right)$ of various cane yielding zones of Theni district of Tamil Nadu.

\begin{tabular}{cccc}
\hline \multirow{2}{*}{$\begin{array}{c}\text { Nample } \\
\text { No. }\end{array}$} & \multicolumn{3}{c}{ CEC $\left(\mathbf{c ~ m o l}\left(\mathbf{p}^{+}\right) \mathbf{k g}^{-1}\right)$} \\
\cline { 2 - 4 } & Low & Medium & High \\
\hline 1 & 13.0 & 19.6 & 36.4 \\
2 & 12.8 & 18.4 & 40.4 \\
3 & 12.6 & 19.3 & 41.2 \\
4 & 9.8 & 18.4 & 58.0 \\
5 & 9.0 & 19.4 & 58.0 \\
6 & 7.8 & 19.0 & 58.0 \\
7 & 14.6 & 17.8 & 27.8 \\
8 & 15.5 & 19.4 & 49.2 \\
9 & 15.4 & 16.9 & 25.3 \\
10 & 14.2 & 16.3 & 20.0 \\
11 & 12.1 & 15.9 & 26.2 \\
12 & 12.1 & 17.0 & 44.8 \\
13 & 11.4 & 18.5 & 43.2 \\
14 & 9.6 & 16.7 & 32.0 \\
15 & 8.4 & 16.5 & 30.6 \\
\hline Max. & 15.5 & 19.6 & 58.0 \\
Min. & 7.8 & 15.9 & 20.0 \\
\hline Mean & 11.9 & 17.9 & 39.4 \\
SD & 2.50 & 1.29 & 12.56 \\
CV & 21.1 & 7.2 & 31.9 \\
\hline
\end{tabular}

block and Usilampatti. The acidic nature of the soils may be due to the oxidation of ammonical fertilizers to nitrate and the leaching of basic cations as reported by Cheong et al. (2010).

The Electrical Conductivity (EC) of surface and sub-surface soil samples of sugarcane growing zones are presented in table 2. The EC values shows that surface soil samples of all the blocks are non-saline in nature. The EC values varied from 0.1 to 0.59 with the mean $\mathrm{EC}$ value of $0.36 \mathrm{dSm}^{-1}$ in the high yielding zone. whereas the EC values of sub surface soil ranges from 0.16 to 0.98 , 0.12 to 0.58 and 0.10 to 1.04 with the mean value of $0.45,0.34$ and $0.33 \mathrm{dSm}^{-1}$ low, medium and high yielding sugarcane growing zones. However, a small increase in EC of the sub surface soils may be due to slight increase in the base saturation of the soil through the salts leached from the soil surface.

The cation exchange capacity of the surface soil samples ranged from 7.8 to $15.5,15.9$ to 19.6 and 20.0 to $58.0 \mathrm{c}$ $\mathrm{mol}\left(\mathrm{p}^{+}\right) \mathrm{kg}^{-1}$ with an average value of $11.9,17.9$ and $39.4 \mathrm{c} \mathrm{mol}\left(\mathrm{p}^{+}\right) \mathrm{kg}^{-1}$ are presented in table 3 . In high yielding zone the highest CEC value of $58.0 \mathrm{c} \mathrm{mol}\left(\mathrm{p}^{+}\right)$ $\mathrm{kg}^{-1}$ was observed in Chinnamanur block while the lowest CEC value of $20.0 \mathrm{c} \mathrm{mol}\left(\mathrm{p}^{+}\right) \mathrm{kg}^{-1}$ was observed in Usilampatti block. An optimum CEC of $15 \mathrm{c} \mathrm{mol}$ $\left(\mathrm{p}^{+}\right) \mathrm{kg}^{-1}$ is suitable for sugarcane cultivation but cation exchange capacity of the soils varied from 7.8 to 15.5 coml $\left(\mathrm{p}^{+}\right) \mathrm{kg}^{-1}$ with a mean value of $11.9 \mathrm{cmol}\left(\mathrm{p}^{+}\right) \mathrm{kg}^{-1}$ in the low soil quality zones. The low percentage of clay and low organic carbon status in these soils are the reasons for low CEC as reported by Sarkar et al. (2002).

Biological indicators of soil: The organic carbon content of the soil ranged from 0.03 to $0.29 \%, 0.06$ to $0.45 \%$, 0.38 to $0.089 \%$ (surface) and 0.04 to $0.25,0.07$ to $0.42,0.26$ to $0.72 \%$ (sub - surface) (Table 4). Our findings found among 225 samples, $100 \%$ of surface soil samples from the low quality zone recorded low organic carbon about 53 percent of soils in high yielding 
Table 4. Soil Organic Carbon (\%) of various cane yielding zones of Theni district of Tamil Nadu.

\begin{tabular}{ccccccc}
\hline Sample & \multicolumn{3}{c}{ Surface soil (0-15 cm) } & \multicolumn{3}{c}{ Subsurface soil (15-30 cm) } \\
\cline { 2 - 7 } No. & Low & Medium & High & Low & Medium & High \\
\hline 1 & 0.12 & 0.25 & 0.45 & 0.09 & 0.17 & 0.30 \\
2 & 0.04 & 0.42 & 0.51 & 0.06 & 0.22 & 0.47 \\
3 & 0.16 & 0.45 & 0.54 & 0.13 & 0.42 & 0.50 \\
4 & 0.19 & 0.28 & 0.42 & 0.17 & 0.21 & 0.32 \\
5 & 0.17 & 0.10 & 0.42 & 0.17 & 0.12 & 0.38 \\
6 & 0.19 & 0.35 & 0.89 & 0.13 & 0.33 & 0.41 \\
7 & 0.29 & 0.41 & 0.44 & 0.19 & 0.26 & 0.58 \\
8 & 0.22 & 0.23 & 0.45 & 0.22 & 0.13 & 0.38 \\
9 & 0.20 & 0.37 & 0.38 & 0.25 & 0.28 & 0.50 \\
10 & 0.03 & 0.16 & 0.53 & 0.12 & 0.32 & 0.60 \\
11 & 0.13 & 0.20 & 0.46 & 0.10 & 0.16 & 0.67 \\
12 & 0.16 & 0.22 & 0.70 & 0.13 & 0.14 & 0.26 \\
13 & 0.07 & 0.15 & 0.62 & 0.06 & 0.12 & 0.50 \\
14 & 0.09 & 0.12 & 0.40 & 0.04 & 0.18 & 0.72 \\
15 & 0.03 & 0.06 & 0.50 & 0.09 & 0.07 & 0.40 \\
\hline Max. & 0.29 & 0.45 & 0.89 & 0.25 & 0.42 & 0.72 \\
Min. & 0.03 & 0.06 & 0.38 & 0.04 & 0.07 & 0.26 \\
\hline Mean & 0.14 & 0.30 & 0.59 & 0.13 & 0.21 & 0.57 \\
SD & 0.08 & 0.12 & 0.13 & 0.06 & 0.10 & 0.13 \\
CV & 54.7 & 43.4 & 31.0 & 46.6 & 46.4 & 28.9 \\
\hline
\end{tabular}

zone recorded low soil organic carbon content ranging between 0.38 and $0.89 \%$. This may be due to the depletion of organic matter under continuous cane cultivation without sufficient addition of organic resources to the soil periodically. Similar such observations have been made by Muhammed Sarwar et al. (2010).

\section{Conclusion}

The results of soil quality indicators in major sugarcane growing blocks of theni district indicated that among 225 samples analyzed, $100 \%$ of surface soil samples from the low quality zone recorded low organic carbon and only less than 6 percent of the soils in high yielding zone had a higher organic content. In surface soil, about 70 percent of the samples from low yielding zone were in acidic $\mathrm{pH}$ range. Whereas, 60 percent of the soils assessed in the high quality zone were under neutral $\mathrm{pH}$ range in most of the cane growing blocks viz., Jeyamangalam, P.C. Patti, Chinnamanur, Andipatti block of Theni district and Usilampatti block of Madurai district. The EC value of surface soil was non-saline in nature. The overall results of the study concluded that higher soil quality category of sugarcane dominant zone of theni district recorded the higher values of soil attributes such as cation exchange capacity, organic carbon. The results also emphasized that improved soil quality is indicated by soil organic matter content which needs top most priority for enhancing sugarcane productivity in low soil quality zone. So, the application of pressmud, vermicompost, biofertilizers, inclusion of legumes/green manuring as intercrops, amendments rich in calcium and magnesium in acidic soil and other amendments rich in sulphur in alkali soils are recommended to maximize productivity of sugarcane.

\section{REFERENCES}

Bower, C.A., Reitmeir, R.F. and Fireman, M. (1952). Exchangeablecation analysis of saline and alkali soils. Soil Science 73:251-261.

Chand,R. (2007). Demand for food grains. Economic and Political Weekly 42 (52): 10 -13.

Cheong, L.R., Keekwong, K.F., Ahkoon, P.D. and Dupreez, C.C. (2010). Influence of sugarcane cropping on the Quality of an Oxisol and an Inceptisol in Mauritius. Communications in Soil Science and Plant Analysis 41: 1205- 1219.

Gomez, K.A. and Gomez, A.A.(1984). Statistical procedures for Agricultural Research, $2^{\text {nd }}$ end. John Wiley Sons, New York. pp. 680.

Gopalasundaram, P., Bhaskaran, A. and Rakkiyappan, P.(2012). Integrated Nutrient Management in sugarcane. Sugar Tech 14 (1): 3-20.

Jackson, M.L. (1973). Soil Chemical analysis, Prentice Hall of India (Pvt.) Ltd., New Delhi.

Muhammad AleemSarwar, Muhammed Ibrahim Muhammad Tahir, Kafeelahamad, Zafar Iqbal khan and Ehsan ElahiValeem. (2010). Appraisal of pressmud and inorganic fertilizers on soil properties, yield and sugarcane quality.Pakistan Journal of Botany 42 (2): 1361- 1367, 2010.

Sarkar, U., Baruah, S.K.,Gangopadhyay, A.K.,Sahoo, and Velayutham, M. (2002). Characteristics and classification of soils of loktak catchment area of Manipur for sustainable land use planning.Journal of Indian Society of Soil Science 50:196 - 204.

Sharma, K.L. and Biswapati Mandal. (2009). Soil Quality and its Relevance for Sustainable Agriculture. Journal of Indian Society of Soil Science 57(4): 572 - 586.

Walkley, A. and Black, C.A.(1934). An estimation of methods for determining organic carbon and nitrogen in the soils. Journal of Agricultural Science 25: 598-609. 